\title{
PROMESAS DIVINAS PARA EL JOVEN DE HOY
}

Peña Salvatierra, Alberto Universidad Peruana Unión albertopena@teologia.edu.pe

Fecha de recepción: Enero 2013

Fecha de aceptación y versión final: Mayo 2013

Texto base: Apocalipsis 22:1-5

Propósito general: Consagración

Palabra clave: Privilegio

Propósito específico: Que valoremos el cielo más que la tierra y a Cristo más que todo placer pasajero, y que dediquemos a Dios nuestras vidas, talentos, tiempo e influencia.

\section{Introducción}

- Saludos y texto. Es un placer saludarlos estimados hermanos, deseando que la paz de Dios abunde en cada uno de ustedes. Agradezco a Dios por el privilegio de tener el mensaje en esta oportunidad. Los invito a abrir juntos la Palabra de Dios en Apocalipsis 22:1-5.

- Titulo. ¿Se dan cuenta de cuán diferente será la vida en esta ciudad edificada por Jesucristo? En estos pasajes, se encuentran preciosas promesas que nos hablan de los privilegios que el hombre gozará 
por la eternidad. Por ello, el presente sermón fue titulado promesas divinas para el hombre de hoy.

- Definición de términos. ¿Qué significa la palabra promesa? Viene del latín promissa, que significa "expresión de la voluntad de dar a alguien o hacer por él algo" (RAE). Entonces, estas promesas de Dios para el hombre de hoy están encerradas dentro de la voluntad de Dios, de darnos ciertos privilegios que serán para nuestra real y completa felicidad y bienestar eterno.

- Ilustración: Ganó una fortuna. El reloj marcaba las 2:17 a.m., en uno de los casinos de Las Vegas. La pequeña multitud allí reunida aguardaba, ansioso el resultado final. Paul Estgate, un joven dinamarqués de 22 años, moreno, de cabellos ondulados, miró hacia todos los lados; respiró hondo; colocó la última carta sobre la mesa... y profirió el grito de victoria. ¡Acababa de ganar 9,15 millones de dólares, en el campeonato mundial de póker!.

- Aplicación de la ilustración. Toda esta alegría vivida por la experiencia de ganar dinero en un instante y al azar, no se compara en nada con lo que nosotros ganaremos cuando Dios nos diga, "Venid benditos de mi Padre, heredad el reino preparado para vosotros desde la fundación del mundo" (Mt 25:34).

- Proposición: Por ello, en esta oportunidad, veremos tres promesas divinas que nos hablan sobre los privilegios que el hombre gozará en la vida eterna. 


\section{Ser ciudadano de una ciudad fantástica}

\section{A. La plaza mayor de esta ciudad será la capital del universo (vs. 1 y 2 ).}

1. En esta ciudad está el trono de la divinidad (vs. 1, 3).

a. Apocalipsis 4:2, 3. Muestra dónde está el trono de Dios, allí está Dios y allí reina y gobierna el universo. En Apocalipsis 4, aparece 12 veces la palabra trono, afirmando su soberanía.

b. Apocalipsis 21:22, 23. Muestra que el Padre y el Hijo, gobiernan la ciudad.

2. Tiene el árbol de vida (v. 2).

a. Este árbol no fue destruido en el diluvio, sino que, poco antes, este árbol y todo el Edén, fue trasladado al cielo.

b. Elena G. de White escribió: "Cuando la ola de iniquidad cubrió al mundo, y la maldad de los hombres trajo su destrucción por medio del diluvio, la mano que había plantado el Edén lo quitó de la tierra. Pero en la final restitución, cuando haya "un cielo nuevo, y una tierra nueva" (Ap 21:1), ha de ser restaurado más gloriosamente embellecido que al principio" (Patriarcas y profetas, 47). 


\section{B. Ciudad sin maldición (v. 3 y 4).}

1. Sin pecado (v. 4; 21:27).

a. El pecado fue el que provocó la división el reino de Dios, pero ahora ha sido extirpado de raíz y rama (Mal 4:1).

b. EGW dice: "La restauración de la unidad perdida. Esto tiene que ser hecho necesariamente en Cristo... La unidad del universo de Dios fue rota por el pecado" (Comentario Bíblico Adventista, 6: 999).

c. Efesios 1:10. Ahora el universo inmaculado será unido con la tierra sin pecado, pero con un cambio sustancial. El centro del universo se ha trasladado a esta tierra.

2. Carácter inmaculado (v. 4).

a. El nombre de Dios estará en las frentes. El imago Dei ha sido recuperado, pero mucho más radiante. "Su nombre estará en sus frentes".

b. Dios había hecho al hombre para su gloria (Is 43. 7), es decir para que reflejara el carácter de Dios al universo, y ahora este plan se cumplirá. El hombre estará en la directa presencia de Dios y verá su rostro.

c. Elena G. de White menciona: "Dios creó al hombre para su propia gloria, para que después de la prueba la familia humana pudiera ser una con la celestial. Era el propósito de Dios repoblar el cielo con la familia humana, si se mostraban obedientes a su Palabra" (Conflicto y valor, 22). 


\section{Ciudad con luz eterna (v.5; cf. 21: 23).}

1. No habrá noche.

a. Por lo visto, la tierra nueva tendrá cambios sustanciales. Una, que no anochecerá.

b. Si no habrá noche, ¿entonces el hombre no necesitará dormir? No lo sabemos, pero lo que sí es cierto, es que las condiciones humanas en la tierra nueva serán mejores.

2. No habrá necesidad de lámpara.

a. La luz del primer día de la creación (Gn 1: 3) alumbrará la tierra. No es la luz de una estrella, sino la luz que viene de Dios, de su gloria, de su santa presencia.

b. ¿Qué maravillosa será esta ciudad con la presencia de Dios iluminándola!

3. No habrá necesidad del sol.

a. Entonces nos preguntamos: ¿La tierra ya no girará alrededor del sol? ¿No estará dentro del sistema solar?

No lo sabemos, pero lo que sabemos es que no habrá necesidad de sol.

b. El hombre será vestido de inmortalidad (1 Cor 15:51-53) y restablecido a la estatura y plenitud de Cristo (2 Cor 3:18). Lleno de vigor y vida, así como fue Adán antes del pecado que era de elevada estatura (Patriarcas y profetas, 23).

c. La Sra. White mencionó que, "los redimidos 
crecerán hasta alcanzar la estatura perfecta de la raza humana en su gloria primitiva". (Conflicto de los siglos, 704). Cambio que hay que buscar desde ahora diariamente.

Aplicación de la sección: Valoremos el cielo más que la tierra y a Cristo más que todo placer pasajero y dediquemos a Dios nuestras vidas, talentos, tiempo e influencia.

\section{Comer del arbol de la vida}

\section{A. Echado del Edén por el Árbol de la vida}

(Gn 3:22, 24).

1. ¿Por qué Adán y Eva fueron expulsados del Edén? Para que no vivan eternamente en el pecado (v. 22).

a. Para que no alargue su mano y coma del árbol (Gn 3: 22, 23).

b. Lo que parecía un castigo, era una protección. Un día, tendrían la oportunidad de comer de este árbol.

c. Pero para ello, Cristo debía ser la expiación.

2. El árbol de la vida era el elíxir de la eterna juventud (v. 22).

a. El árbol de la vida tiene la propiedad de mantener el vigor y la eterna juventud.

b. Ilustración: Ponce de León y la fuente de la juventud. Según una leyenda, Ponce de 
León descubrió Florida buscando la fuente de la juventud, aguas que devolvían la vitalidad. También la había buscado en la India, búsqueda infructuosa que la mantuvo hasta su muerte en 1521.

c. Aplicación: El elixir de la juventud o vida eterna se podrá encontrar solo en el árbol de la vida, y el requisito para participar de él, es abandonar el pecado y vivir en Cristo.

d. El cristiano hoy, simbólicamente puede participar de este árbol, recibiendo y viviendo en Cristo, quien es el pan de vida.

3. El pecado cerró el camino al árbol de la vida (v. 24).

a. ¿Qué es lo que hizo separación entre el hombre y Dios? Leamos Isaías 59: 2. Nuestros pecados.

b. El pecado separa de Dios y trae muerte (Rm 6: 23). Que Dios nos ayude a odiar el pecado y a separarnos de él, para estar con Dios siempre.

c. Hoy Cristo es nuestra fuente de vida eterna (Jn 6: 51, 54).

\section{B. El camino al árbol de la vida restablecido}

\section{(Ap 22: 2).}

1. Las raíces, el tallo, las ramas y los frutos de árbol de la vida da a los dos lados del río, y en la vida eterna, el hombre tendrá libre acceso al árbol de la vida. ¿Saben qué significa esto? Es nuestra garantía de vida eterna. 
a. Ilustración: El positivismo y la utopía. Grandes pensadores como Marx, Comte, Russel, Lenin y otros soñaron con una sociedad justa, equitativa, de paz y abundancia donde haya armonía, amor y vida continua. Pero todo quedó en un positivismo utópico, porque nunca vieron esa sociedad.

b. Aplicación. Ellos se olvidaron de un gran problema humano, el pecado. Mientras el pecado siga activo y campante entre los hombres, nunca encontraremos una sociedad así. Pero Dios nos promete cielos y tierra nueva, donde habite la justicia, el amor y la prosperidad.

2. Lleno de salud. El versículo dice (Ap 22: 2), "era para la sanidad de las naciones". Esto significa, no solo eterna juventud, sino lleno de salud, vida, sin dolor sin enfermedad.

a. Sanidad viene del griego "terapeían" que puede ser traducido como "terapia, salud, curación". La NVI traduce mejor así: "las hojas del árbol son para la salud de las naciones".

b. No para curar o dar sanidad al enfermo, porque no habrá enfermedad. No. La idea es para conservar la salud física y mental permanentemente.

\section{C. ¿Quiénes tendrán derecho a comer del árbol de la vida? (v. 14).}

1. Los que lavan sus ropas. 
a. ¿Cuándo lavan sus ropas? Por lo visto, la salvación no se decidirá en el futuro, sino ahora en el presente, porque el verbo lavar, no está en futuro, sino en presente, lo cual quiere decir que es ahora cuando debemos decidir lavar nuestras ropas.

b. ¿Dónde lavan las ropas? Veamos Apocalipsis 7: 14. Lavaron sus ropas en la sangre del Cordero.

2. ¿Qué significa lavar las ropas en la sangre del Cordero? Apocalipsis 7: 15, 17.

c. Estar delante de Dios.

d. Servirle día y noche.

e. Permitir que Cristo sea su pastor.

3. Vestido con las acciones justas de los santos (Ap 19: 8).

a. Lino fino. Un símbolo de la justicia o rectitud del carácter (cf. cap. 3: 5; 6: 11; ver cap. 3: 18; cf. cap. 22: 14, CBA, 7).

b. Limpio. Mejor "espléndido"; brillante y refulgente, como la luz de una lámpara (Lc 23: 11 y Ap. 22: 16).

Aplicación de la sección: Valoremos el cielo más que la tierra y a Cristo más que todo placer pasajero y dediquemos a Dios nuestras vidas, talentos, tiempo e influencia. 


\section{Vivir con el padre y el hijo por la eter- nidad}

\section{A. Dios Padre y Dios Hijo (22: 1).}

1. El río de la vida sale del trono del Padre y del Hijo (Ap 22: 1pp).

a. El Padre y el Hijo son la fuente de vida y armonía en el universo. (22: 1up).

b. ¿Y el Espíritu Santo dónde está? Según Génesis 1:2, "moviéndose", es decir, está sosteniendo el universo porque es la parte ejecutiva de Dios. Pero está allí también, aunque no se menciona su trono, Él está también dando gozo a los redimidos y sosteniendo su creación.

c. El Espíritu Santo es Dios omnipresente activo sustentador del universo (Sal 139: 7, 8).

d. El hombre y Dios cara a cara (Ap 22: 4).

e. El hombre verá cara a cara a Dios, siendo el Hijo el Dios visible.

f. El Padre será esa luz resplandeciente (Ap 22: $5 \mathrm{~d})$.

B. El mayor gozo del hombre será servir a Dios (Ap 22: 3up).

1. Servicio que brota de la gratitud de la salvación.

a. Ilustración. El esclavo rebelde. En el mercado decía, no me compren, porque no les voy servir. Yo quiero ser libre. Un hombre 
adinerado lo compró a pesar de sus amenazas. Cuando llegó a su finca. El esclavo lo amenazaba que en cualquier momento se escaparía, que había malgastado su dinero. El hombre adinerado lo hizo desatar y luego le entregó un documento donde le daba la completa libertad. El esclavo salió, y estando afuera se dijo, ¿a dónde iré? Un hombre tan bueno, no encontraré en ningún lugar. Así, se volvió y se hizo su esclavo voluntario.

b. Aplicación. El AT contemplaba esta situación. Aquel que se hace esclavo voluntariamente quedaba como tal de por vida. Veamos Éxodo 21: 5, 6.

c. En la vida eterna, será nuestro mayor gozo vivir y ver a Dios cara a cara.

2. Servicio que brota de recibir tanto tan inmerecidamente.

a. Solo gratitud y admiración por su Dios misericordioso.

b. Dios es el centro del hombre.

3. Servicio que brota al reconocer el alto precio que se pagó.

a. Gratitud y admiración por el insondable amor de Dios.

b. Gratitud que por los siglos se seguirá conociendo y ampliando. 


\section{A. La felicidad eterna está garantizada (22: 5up).}

1. No queda ni raíz ni rama del pecado (Mal 4: 1).

a. Con tremenda experiencia vivida de dolor y miseria, nunca nadie más se atreverá a revelarse y nunca más se levantará el pecado.

b. Dios garantiza que el mal y el dolor nunca más se levantarán por la eternidad en todo su universo.

2. El hombre y Cristo estarán emparentados por la eternidad.

a. Cristo tomó la humanidad con lazos que nunca se romperán.

b. Cristo será Dios y Hombre por la eternidad, y nosotros sus hermanos, hijos e hijas del Rey.

Aplicación de la sección: Valoremos el cielo más que la tierra y a Cristo más que todo placer pasajero y dediquemos a Dios nuestras vidas, talentos, tiempo e influencia.

\section{Conclusión}

- Recapitulación: En conclusión, recapitulando, recordemos los privilegios que el hombre gozará en la vida eterna:

$\checkmark$ Dios nos promete la ciudadanía de una ciudad fantástica,

$\checkmark$ Dios nos promete que comeremos del árbol de la vida $y$, 


\section{$\checkmark$ Dios nos promete pasar la eternidad en su inmediata presencia.}

- Aunque gozaremos de estos privilegios en la tierra renovada, sin embargo, hoy y ahora podemos empezar a disfrutar de estas promesas.

- Llamado: Los invito a tomar la firme decisión de disfrutar ahora de estos privilegios de la vida eterna.

$\checkmark$ Vivamos como ciudadanos de la Nueva Jerusalén ahora.

$\checkmark$ Vivamos en Cristo quien es el pan de vida, anticipo del árbol de la vida eterna.

$\checkmark$ Vivamos delante de la presencia de Dios constantemente.

- Propósito específico: Estimados, ¿qué debemos hacer ahora? Consagrémonos a Dios: Valoremos el cielo más que la tierra y a Cristo más que todo placer pasajero, y dediquemos a Dios nuestras vidas, talentos, tiempo e influencia.

- Forma de compromiso: En estos momentos les invito a renovar su compromiso con Dios escribiendo en una hoja su pacto de fe. 